\title{
The Relationship Between Exposure to Media Violence and School Bullying in Jordan
}

\author{
Nesrin N. Abu-Baker ${ }^{1} \&$ Saleh Nasser Ayyd ${ }^{1}$ \\ ${ }^{1}$ School of Nursing, Jordan University of Science \& Technology, Irbid, Jordan \\ Correspondence: Nesrin N. Abu-Baker, School of Nursing, Jordan University of Science \& Technology, P.O.Box \\ 3030, Irbid 22110, Jordan. Tel: 962-2-720-1000-23605. E-mail: nesrin@just.edu.jo
}

Received: March 14, 2018 Accepted: April 7, 2018 Online Published: April 19, 2018

doi:10.5539/gjhs.v10n5p154 URL: https://doi.org/10.5539/gjhs.v10n5p154

\begin{abstract}
Purpose: To examine the relationship between exposure to media violence and bullying among school students in Jordan.

Method: A cross-sectional, correlational design and a self-reported questionnaire were used to answer research questions. A multistage, stratified random sampling was utilized to recruit a sample of 550 students from eight governmental educational directorates in a large governorate in Jordan. A self-reported questionnaire included demographic data, Media Violence Exposure scale, and School Bullying scale was distributed.
\end{abstract}

Results: Prevalence of school bullying was $47 \%$. There was a positive correlation between media violence exposure and school bullying $(r=.549)$; significantly more boys reported exposure to media violence, perpetrating of school bullying in general, and perpetrating of physical bullying in particular than girls $(p=.00)$. While significantly more girls reported perpetrating of relational bullying than boys $(p=.00)$. Media violence viewing time explained $42 \%$ of variance in school bullying scores.

Conclusion: The findings call urgent need for intervention programs tailored by specialized health professionals to combat the consequences of this growing phenomenon.

Keywords: media violence, bullying, school bullying, Jordan

\section{Introduction}

Violence has been found in all societies, it represents a serious problem which concerns all populations (Tharp, Simon, \& Saul, 2012). Violence tends to generate more aggressive behaviors such as school bullying which causes multiple social problems. This in turn will create obstacles to the integral development of population, especially children and adolescents (Orue et al., 2011). School bullying is a phenomenon that occurs in an educational setting and is common in adolescence. Adolescents need to feel accepted by peers in school, where adolescents spend a large amount of time and maintain personal relationships (Ismail, Jaafar, Sidi, Midin, \& Shah, 2014).

Nowadays; large amount of violence is daily depicted in different forms of popular media. Media field is ever changing; with new technology, different media forms such as TV, movies, videogames, social media websites, and internet became very attractive (Media Violence Commission, 2012). Media represent one of the most significant and powerful tools that influences children and adolescents' development and health. They have unstable developmental status, adding to that considerable long time to spend with different forms of violent media, which make them more susceptible (Ukoha, 2013).

Exposure to media violence has been related to aggressive behavior, hence; it is plausible that it will lead to bullying as less severe form of aggressive behavior (Dittrick, Beran, Mishna, Hetherington, \& Shariff, 2013). Bullying is considered a significant social problem worldwide (Hong \& Espelage, 2012). Previous research provided evidence for the relationship between violent media exposure and school bullying (Den Hamer \& Konijin, 2015; Dittrick et al., 2013; Fanti, Demetriou, \& Hawa, 2012). Growing body of evidence for the correlation between large prevalence of both school bullying in one hand, and the great and easy access of children and adolescents to different forms of violent media on the other hand, is continuously urging public, researchers, and policy makers to further investigate this association. Which in turn will enable them to devise preventive measures to stop further school bullying and other delinquent behaviors (Ttofi \& Farringto, 2011). 
As shown by literature, there is an ample cross-sectional and longitudinal evidence from the literature for the association between exposure to media violence and school bullying (Dittrick et al., 2013). Despite this fact, the topic of exposure to media violence effect on school bullying among adolescents is still ignored in Jordan and some other eastern countries. Gap remains in our knowledge of the relationship between violence in the media and school bullying in Jordan.

The major purpose of this study is to examine the relationship between exposure to different types of violence at different media forms (TV, movies/DVD/ videos, and video/ computer- games) and expression of school-bullying (physical, verbal and relational/social) among school students in Jordan. This study aims to answer the following research questions:

1) What is the relationship between exposure to media violence and school-bullying among school students in Jordan?

2) How much variance in school bullying scores could be explained by variance in the students' weekly media violence viewing time in hours?

3) What is the difference in media violence exposure scores between school students who are males or females?

4) What is the difference in school bullying scores between school students who are males or females?

5) What is the difference in specific forms of school bullying scores (physical, verbal, and relational scores), between school students who are males or females?

\subsection{Study Significance}

The significance for this study emerges from the fact of high prevalence rate of school bullying in Jordan which is nearly 47\% (Al-Betar, Al-Omari, Sonbol, Al-Ahmad, \& Cunningham, 2013). Examining the association between school bullying and other important risk factors such as gender and adolescents' repeated exposure to media violence, will reveal the link between them. Results of this study will reveal the crucial role of school health nurse in developing media literacy programs for children and adolescents. These programs could be directed toward protecting them from the vicious health consequences of media violence exposure. This will in turn provide safe and supportive school environment for learning, and healthy development.

\subsection{Literature Review}

Exposure to different forms of media such as TV, movies, music videos, internet websites, and videogames is considered the major leisure time for most children and adolescents worldwide. For example, in 2015, 25\% of American high school students watched television for three hours or more on a regular school day. Furthermore, the percentage of students who used computers three or more hours per day significantly increased between 2003 and 2009 from $22 \%$ to $25 \%$. It also increased very quickly between 2009 and 2015 from $25 \%$ to $42 \%$ (Centers for Disease Control and Prevention [CDC], 2015). In Netherlands, a study conducted by Fikkers, et al. (2013) found that on average, adolescents reported consuming 4.8 hours per a week of violence in TV and videogames. On the other hand, a study was conducted in Nigeria to examine pattern of media using among Nigerian youths; it was found that the matter is not better in low income countries such as Nigeria. Most children and adolescents between five to 20 years old, spent over six hours a day using entertainment media which contained high level of violence (Ukoha, 2013).

Bulling is a unique form of aggression. It is a wide spread interpersonal/within group phenomenon, and it occurs in different social context, such as community, workplace, and school (Verlinden et al., 2014). Although bullying is a common problem among children and adolescents; majority of studies focused on bullying in the community and workplace, with little attention given to school bullying among very sensitive and vulnerable age groups: children and adolescents. Due to rapid advance of media technology, such as 24 hours online internet websites and online videogaming, the association between media violence and subsequent aggressive behavior has become the focus of research on areas of personality, social psychology and health (Lam, Cheng, \& Liu, 2013).

A correlational study utilized a national representative sample in Canada. The aim was to examine whether children who bully others are likely to prefer playing videogames that are violent and rated high in maturity. A stratified random sample of 1000 children (aged 10 to 17 years) and their parents from 10 provinces was obtained. They completed an online survey of children's bullying behavior, and their favorite three videogames. The results showed that boys prefer violent and high rated maturity videogames more than girls $(p<.05)$, also they are more perpetrating for general bullying, physical bullying, verbal bullying than girls $(p<.05)$. Furthermore, the results clearly revealed that both parents' and children's reports of preference for mature and violent videogames were significantly related to children perpetration of bullying $(p<.05)$ (Dittrick et al., 2013). 
Researchers have identified several characteristics for bullying behavior, which formulate several subcategories for bullying such as direct and indirect bullying. Direct form encompasses a) Physical bullying which includes hitting, pushing, shoving, tripping, kicking, spitting, unwelcome touching, forcing others to do something, having a money or other things taken or damaged or breaking belongings, b) Verbal bullying includes teasing, name-calling, taunting, threating, and making derogatory comments. The indirect bullying encompasses relational / social bullying which includes intentional exclusion from group, isolation, spreading lies and hurtful rumors, and making offensive religious or racial or sexual jokes, comments, or gestures (Kazarian \& Ammar, 2013).

Although bullying is considered a global problem with vicious consequences that affect both western and eastern countries, most studies which thoroughly investigated this problem were conducted in western countries, while few were conducted in eastern countries. Moreover, School bullying tends to occur in different settings in and out of schools, such as classroom, playground, hallway, gym, canteen, and toilets (Kazarin \& Ammer, 2013). A study was conducted by Al-Bitar et al. (2013) in Jordan, it recruited a representative random sample of 920 sixth-grade students aged 11 to 12 years in Amman. The results showed that the prevalence of school bullying was $47 \%$ for being a victim of bullying, and $35 \%$ for bullying someone else (significantly more boys than girls reported being a victim of bullying, as well as, bullying someone else, $p<.001$ ). Another cross-sectional study was performed using 366 Brazilian adolescents between 13 and 15 years. Verbal school bullying was measured using a national school-based health survey. The results showed that $18 \%$ of adolescents were aggressors. $5.5 \%$ were victims, and $2.7 \%$ were both aggressors and victims. Most aggressors were males ( $\mathrm{PR}=1.97,95 \% \mathrm{CI}: 1.23-3.14)$ (Serra-Negra, et al., 2015). Finally, in 2015 in the United States, $20 \%$ of high school students reported that they had been bullied on school property during the 12 months before a nationwide survey (CDC, 2015).

\section{Methods}

\subsection{Research Design}

A cross-sectional, correlational design was used in the actual study to investigate the relationship between exposure to violence at different media forms (TV, movies/DVD/videos, and video/computer- games) and expression of school bullying among school students in Jordan.

\subsection{Research Setting}

The actual study was conducted in governmental educational directorates of Irbid governorate including male and female schools. Irbid is the second largest city in Jordan, with population size about 1,770,158 inhabitants divided into nine counties (Department of Statistics-Jordan, 2015).

\subsection{Population and Sample}

The target population for the actual study is all students in the $6^{\text {th }}, 7^{\text {th }}$, and $8^{\text {th }}$ grades affiliated with governmental educational directories of all Jordanian governorates. While the accessible population was all students in $6^{\text {th }}, 7^{\text {th }}$, and $8^{\text {th }}$ grades in the selected schools in the educational directorates of Irbid governorate.

A multistage, stratified random sampling technique was used to recruit the study sample. At first stage; a list of all governmental schools was obtained from the eight educational directorates in Irbid governorate. For each educational directorate, the schools were stratified in term of gender into two strata: males' schools and females' schools. Two schools were randomly selected: one school from males' schools stratum, and one from females' schools stratum. In the second stage; three classes $\left(6^{\text {th }}, 7^{\text {th }}\right.$, and $\left.8^{\text {th }}\right)$ were randomly selected from each selected school. In third stage; 12 students were randomly selected from each selected class. The total sample size was 570 participants at $6^{\text {th }}, 7^{\text {th }}$, and $8^{\text {th }}$ grades.

The inclusion criteria consisted of all Jordanian students, who were at the $6^{\text {th }}, 7^{\text {th }}$, or $8^{\text {th }}$ grades, who were physically able to fill the questionnaire, and who had consent form from their parents donating their approval.

\subsection{Measurement}

A structured self-report questionnaire was used in the actual study to examine the relationship between exposure to media violence at different media categories (TV, movies/ DVD/ videos, and video/ computer- games) and expression of school bullying (physical, verbal, and relational/social).

This anonymous self-report questionnaire had three subscales: Socio-demographic Characteristics Scale, Media Violence Exposure Scale, and School Bullying Scale. In addition to instructions to the respondents, and consent form.

The questionnaire was translated to Arabic language, then retranslation from Arabic language to English language was done by a person who knows both languages very well to assure validity of the translation process. The 
questionnaire was tested by a panel of experts to assess its comprehensibility, clarity, readability, face and content validity, before starting data collection process. Minor changes were made to the questionnaire's items as indicated.

Socio-demographic characteristics scale was developed by the researcher to collect information about the participants' background. It included questions about participants' age, gender, grade, father's level of education, mother's level of education, father's job, mother's job, and total monthly family income.

In the current study, media violence exposure was measured using a modified version of Content-based Media Exposure Scale (C-ME) which was developed by Den Hamer, Konijn, and Keijer (2014). Content-based Media Exposure Scale was an anonymous self-report scale which consisted of 22 items to measure how often someone watches portrayals of various anti-social media content such as violence, sex, drug abuse, and other general anti-social behaviors (e.g., stealing, shooting someone, and destroying someone else's property) regardless the type of media that was consumed (e.g., TV, internet, videogames). For the purpose of the current study a modified version of C-ME was adopted by the researcher to assess the respondents' exposure to violence across three types of media: TV, movies/ videos/ DVD, and video/ computer-games. The modified-version from C-ME consists of seven items to measure different types of violent/aggressive acts such as murder (e.g., stabbing, or shooting someone), destroying someone else's properties, fighting, robbery (using knife, gun, or any other king of weapons), and aggravated assaults (e.g., threating someone with weapons, or attaching someone resulting in the need for medical care). For the first six items, participates were asked to rate how often they watched/ played different violent acts on 5-points Likert scale ranged from $1=$ less than every other week, $2=$ every other week, $3=2-3$ times a week, $4=$ every other day, and $5=$ every day. While in the $7^{\text {th }}$ item in the scale, the participants were asked to specify how long they normally watched/played this media type in an average week. For each participant, Media Violence Exposure Scale was used to assess exposure to violence at three media forms: TV, movie/ video/ DVD, and video/ computer-games. Total score of Media Violence Exposure Scale ranged from 6 to 30; the higher the score, the more media violence exposure. The Cronbach's Alpha value for the Media Exposure Scale was reported in the literature to be equal to .84 (Konijn, Veldhuis, Plaisier, Spekman, \& Den Hamer, 2015).

School bullying behavior in the current study was measured using modified version of School Life Survey (Chan, 2002). The original version of School Life Survey consisted of two subscales: bullying scale and victimization scale, each of which contained different items to measure the three forms of school bullying: physical, verbal, and relational (social) bullying. Bullying sub-scale had nine items, whereas Victimization sub-scale had 15 items. For the purpose of the current study; a modified, anonymous, and self-report version of School Life Survey was adopted by the researcher to assess respondents' experiences of the three forms of school bullying: physical, verbal, and relational (social) bullying. School Bullying Scale (the modified-version of School Life Survey) consisted of 10 items to measure different forms of school bullying: a) physical bullying was measured by items of 2, 5, and 8; b) verbal bullying was measured by items of 3,6, and 9; c) relational (social) bullying was measured by items of 4 , 7, and 10. The first item in School Bullying Scale was multiple-choice question, inquired about perpetration of school bullying in general, whereas the remaining nine items were a Likert-type scale rated by the respondents in five-points ranged from 1=Never; $1=$ Once or twice; $2=2-3$ times a month; $3=$ about once a week; $5=$ several times a week. Total score of School Bullying Scale ranged from 10 to 50; the higher the score, the more Validity and reliability of the instrument.

Before conducting the actual study, a pilot study was carried out to estimate the precise amount of time needed for the participants to fill in the questionnaire, to determine whether the questions are clear, readable, easy to understand, and relevant to them. Furthermore, face validity and reliability of the scales and practical limitations of the instruments were checked. The pilot study was conducted in two governmental schools affiliated to one directorate in Irbid governorate; one school for boys and the other for girls. Three classes $\left(6^{\text {th }}, 7^{\text {th }}\right.$, and $8^{\text {th }}$ grades $)$ were randomly selected from each selected-school. From these classes, 85 students were randomly selected (43 males, and 42 females), and were asked to read the participant's information sheet, then give their voluntary-verbal approval to participate before starting to fill in the questionnaire.

From the total of 85 students who participated, 76 completed the questionnaire. About 54\% of the pilot sample were males, and about $46 \%$ were females. Twenty to twenty-five minutes was the needed time to fill out the questionnaire. All the items were clear, readable, and easy to understand. Cronbach's alpha for media violence exposure scale was 0.89 and for school bullying scale was 0.79 .

\subsection{Ethical Consideration and Data Collection Procedure}

Ethical approval to conduct this study was obtained from the Institutional Review Board at the researcher's University. Permissions to collect participants' data were obtained from all governmental educational directorates 
in Irbid governorate after attaining approval of Jordanian Ministry of Education. The actual study was carried out in October 2016 in Irbid governmental educational classes', and the researcher collected the participants' data after the informed consent form each participant's parents was singed.

The researcher met each school principal to explain the purpose of the current study, and get permission to meet the students in their classrooms. The purpose of this study and the procedures were explained to the students. In addition, the students were assured that their participation in the current study is totally voluntary and anonymous. The students were assured that they can withdraw at any time without any penalty of withdrawing. Also, the students were informed that the data will be treated as confidential, and only the researcher will have an access to the collected data. During data collection time, the researcher and only one school teacher were found in the class. The students whose parents signed the informed consent, and who voluntary completed the questionnaire were enrolled in the study.

\subsection{Data Management and Analysis}

After the data was collected from the actual study participants, Statistical Package of Social Science (SPSS) version 20, was used for the purpose of data entry, manipulation and analysis. Collected-data were cleaned and screened for any incomplete or missing data.

Descriptive statistics were used to draw summaries including computation of means, standard deviations, frequencies of the study variables, and descripting the socio-demographic characteristics of the participants. Additional bivariate analysis such as Pearson Correlation Coefficient, Standard Multiple Regression and Independent T-test were used to answer the research questions.

\section{Results}

\subsection{Socio-Demographic Characteristics of Participants}

Five hundred and seventy questionnaires were distributed to the actual study participants all over the eight educational directorates in Irbid governorate. Five hundred and sixty-two questionnaires were returned (response rate was about 98.6\%). However, twelve questionnaires were excluded due to missing data. The total number of included questionnaires was 550 .

From the total sample of the actual study, $52 \%$ of the students were females. Age of students ranged between $11-15$ years $(M=12.33, S D=1.00)$. Sixteen schools were randomly selected representing $6^{\text {th }}, 7^{\text {th }}$, and $8^{\text {th }}$ grades in all governmental schools in Irbid governorate. Demographic characteristics are shown in Table 1.

Table 1. Socio-demographic Characteristics of the Study Sample

\begin{tabular}{lll}
\hline Variable & $\begin{array}{l}\text { Frequencies } \\
\text { (n) }\end{array}$ & $\begin{array}{l}\text { Percentages } \\
\mathbf{( \% )}\end{array}$ \\
\hline Gender & 264 & $48 \%$ \\
Male & 286 & $52 \%$ \\
Female & & \\
\hline Grade & 186 & $33.8 \%$ \\
$6^{\text {th }}$ & 175 & $31.8 \%$ \\
$7^{\text {th }}$ & 189 & $34.4 \%$ \\
$8^{\text {th }}$ & & \\
\hline Father level of education & 121 & $22.0 \%$ \\
Less than high school & 211 & $38.4 \%$ \\
High school & 218 & $39.6 \%$ \\
Diploma or University degree & & \\
\hline Mother Level of education & 87 & $15.8 \%$ \\
Less than high school & 204 & $37.1 \%$ \\
High school & 259 & $47.1 \%$ \\
Diploma or University degree & & \\
\hline
\end{tabular}




\begin{tabular}{lcc}
\hline Father's job & & \\
Private/Vocational & 137 & $24.9 \%$ \\
Governmental/military & 304 & $55.3 \%$ \\
Others & 109 & $19.8 \%$ \\
\hline Mother's job & & \\
Employed & 163 & $29.6 \%$ \\
Unemployed & 387 & $70.4 \%$
\end{tabular}

\section{The Relationship between Exposure to Media Violence and School Bullying among School Students in Jordan}

This section is intending to answer the first research question in this study, which stated "What is the relationship between exposure to media violence and both school bullying among school students in Jordan?"

Results of Pearson's product-moment coefficient of the current study revealed a statistically significant relationship between total media violence exposure and school bullying among the participants $[r=.549, n=550$, $p=.00]$.

Furthermore, the results of the present study revealed a statistically significant relationship between the three media violence exposure subscales and school bullying scale among the participants. Videogames Violence Exposure subscale (VGVE) had a positive relationship with school bullying scale $[r=.515, n=550, P=.00]$, TV Violence Exposure subscale (TVVE) had a positive relationship with school bullying scale $[r=.430, n=550$, $P=.00]$, and Movies/ DVD/ Videos Violence Exposure subscale (MDVVE) had a positive relationship with school bullying scale $[r=.283, n=550, P=.00]$.

\section{Variance in School Bullying Scores as Explained by Variance in Weekly Media Violence Viewing Time in hours}

This section answered the second research question which stated "How much variance in school bullying scores could be explained by variance in students' weekly media violence viewing time?"

The results of standard multiple regression revealed that there was a statistically significant relationship (positive correlation) between weekly media violence viewing time scores and school bullying scores $[r=.653, n=550$, $P=.00]$. Value of adjusted R Square equaled 0.42 . This indicated that $42 \%$ of variance in school bullying scores was explained by the effect of weekly media violence viewing time for the participants.

\section{Differences in Media Violence Exposure Scores between Male and Female School Students}

Means and standard deviations of each item in media violence exposure scale are shown in Table 2.

Table 2. Means and Standard Deviations of Items in Media Violence Exposure Scale ( $\mathrm{N}=550)$

\begin{tabular}{|c|c|c|}
\hline Variable & Mean & $\begin{array}{l}\text { Standard } \\
\text { Deviation }\end{array}$ \\
\hline Media Violence Exposure Scale & 48.16 & 15.65 \\
\hline A) TV Violence Exposure & 17.99 & 6.73 \\
\hline - Destroy someone else's property. & 3.16 & 1.50 \\
\hline - $\quad$ Murder someone else (e.g., stabbing, shooting). & 2.94 & 1.52 \\
\hline $\begin{array}{l}\text { Aggravated assaults (e.g., threating someone with a weapon, or attacking someone } \\
\text { resulting in the need for medical care). }\end{array}$ & 2.95 & 1.54 \\
\hline - $\quad$ Robbery using a knife, a gun, or other kind of weapons such as bat. & 2.47 & 1.42 \\
\hline - $\quad$ Fighting. & 3.19 & 1.51 \\
\hline - How often do you watch these shows in course of the week? & 3.28 & 1.38 \\
\hline B) Movies/DVD/videos Violence Exposure & 11.13 & 6.79 \\
\hline - Destroy someone else's property. & 1.89 & 1.32 \\
\hline
\end{tabular}


- $\quad$ Murder someone else (e.g., stabbing, shooting).

1.82

1.29

- Aggravated assaults (e.g., threating someone with a weapon, or attacking someone resulting in the need for medical care).

- $\quad$ Robbery using a knife, a gun, or other kind of weapons such as bat.

$1.90 \quad 1.35$

- Fighting.

$1.71 \quad 1.20$

$1.94 \quad 1.38$

- How often do you watch these shows in course of the week?

$1.87 \quad 1.26$

$19.03 \quad 7.33$

$3.48 \quad 1.57$

$3.18 \quad 1.55$

- Murder someone else (e.g., stabbing, shooting).

$3.13 \quad 1.61$ resulting in the need for medical care).

- $\quad$ Robbery using a knife, a gun, or other kind of weapons such as bat.

$2.57 \quad 1.46$

- Fighting.

$3.32 \quad 1.5$

- How often do you watch these shows in course of the week?

The third research question stated "What is the difference in media violence exposure scores between male and female school students in Jordan?" An independent t-test was conducted to examine the difference in total media violence exposure scale's scores, as well as its three subscales' scores, between males and females. The study results showed that there was a statistically significant difference in total media violence exposure scores between males $(M=51.50, S D=15.33)$ and females $(M=45.07, S D=15.33) ;[t(544.48)=4.91, p=.00]$. However, regarding the three media violence exposure subscales, only two showed a significant difference: Movies/DVD/Videos violence exposure, and Videogames violence exposure $([t(503.64)=3.81, p=.00],[t(546.99)=7.75, p=.00]$ respectively). Overall, these results indicated that male and female school students had different levels of exposure to violence which is depicted by different media types (males were more exposed to violence in video/computer-games, as well as, in Movies / DVD / Videos than females). On the other hand, both genders had equal level of exposure to violence in TV (Table 3).

Table 3: Comparison between Male and Female Students' in terms of Media Violence Exposure

\begin{tabular}{llllll}
\hline Variables & M & SD & T & df & P-value \\
\hline Media violence exposure & 48.16 & 15.65 & 4.91 & 544.48 & 0.00 \\
Male & 51.50 & 15.33 & & & \\
Female & 45.07 & 15.33 & & & \\
\hline TV violence exposure & 17.99 & 6.73 & -6.34 & 542.84 & 0.52 \\
Male & 17.80 & 6.79 & & & \\
Female & 18.16 & 6.68 & & & \\
\hline Movies/DVD/videos violence exposure & 11.13 & 6.79 & 3.81 & 503.64 & 0.00 \\
Male & 12.28 & 7.44 & & & \\
Female & 10.07 & 5.96 & & & \\
\hline Videogames violence exposure & 19.03 & 7.33 & 7.75 & 546.99 & 0.00 \\
Male & 21.42 & 6.51 & & & \\
Female & 16.83 & 7.36 & & & \\
\hline
\end{tabular}

Note: Sig. P-value is less than or equal to. 05

\section{Differences in School Bullying between Jordanian School Students in terms of their Gender}

Means and standard deviations of each item in school sullying scale are shown in Table 4. 
Table 4. Means and Standard Deviations of Each item in School Bullying Scale ( $\mathrm{N}=550)$

\begin{tabular}{|c|c|c|}
\hline Variable & $\begin{array}{l}\text { Mean } \\
\text { (M) }\end{array}$ & $\begin{array}{l}\text { Standard Deviation } \\
\text { (SD) }\end{array}$ \\
\hline \multirow{2}{*}{$\begin{array}{l}\text { School bullying scale } \\
\text { - During your previous grade, how often have you } \\
\text { been taken part in bullying another student(s) } \\
\text { either at school or in the way to or from the } \\
\text { school? }\end{array}$} & 20.35 & 7.27 \\
\hline & 2.87 & 1.37 \\
\hline - I hit or beat up other student(s) and hurt him/ her. & 1.89 & 1.24 \\
\hline $\begin{array}{l}\text { - I teased other student(s) and made cruel jokes } \\
\text { about him/her. }\end{array}$ & 2.34 & 1.31 \\
\hline $\begin{array}{l}\text { I kept this/those I didn't like from joining in play } \\
\text { time or group activities. }\end{array}$ & 1.63 & 1.06 \\
\hline $\begin{array}{l}\text { I took things from other student(s) and did not } \\
\text { give him/her back. }\end{array}$ & 1.82 & 1.24 \\
\hline - I told other student(s) that I would hurt him/ her. & 1.97 & 1.26 \\
\hline $\begin{array}{l}\text { I told lies and stories about other student(s) to } \\
\text { make him/her look bad. }\end{array}$ & 1.49 & 0.94 \\
\hline $\begin{array}{l}\text { - I pushed other student(s), made him/her fall and } \\
\text { get hurt. }\end{array}$ & 2.16 & 1.40 \\
\hline $\begin{array}{l}\text { - I said mean things about other student(s) and } \\
\text { called him/her bad names. }\end{array}$ & 2.69 & 1.41 \\
\hline $\begin{array}{l}\text { I kept other student(s) from being friends with } \\
\text { people I didn't like }\end{array}$ & 1.50 & 0.93 \\
\hline
\end{tabular}

The fourth research question was "What is the difference in school bullying between school students who are males or females? "An independent t-test was conducted to examine the difference in school bullying scores between adolescent students who are males and females. The results showed that there was a statistically significant difference in scores between males $(M=22.18, S D=7.59)$ and females $(M=18.66, S D=6.53)$; $[t$ $(520.97)=5.80, p=.007$. Regarding school bullying, generally, these results revealed that male and female adolescent students had different levels of perpetrating of school bullying; males were more perpetrators for school bullying than females.

Differences in Specific Forms of School Bullying (physical, Verbal, and Relational) between School Students Who are Males or Females

Means and standard deviations of physical, verbal, and relational (social) bullying scales are shown in Table 5 . 
Table 5. Means and Standard Deviations of Physical, Verbal, and Relational (social) Bullying Scales ( $\mathrm{N}=550$ )

\begin{tabular}{|c|c|c|}
\hline Variable & $\begin{array}{l}\text { Mean } \\
\text { (M) }\end{array}$ & $\begin{array}{l}\text { Standard Deviation } \\
\text { (SD) }\end{array}$ \\
\hline Physical Bullying & 5.86 & 3.17 \\
\hline - I hit or beat up other student(s) and hurt him/ her. & 1.89 & 1.24 \\
\hline - $\quad$ I took things from other student(s) and did not give him/her back. & 1.82 & 1.24 \\
\hline - $\quad$ I pushed other student(s), made him/her fall and get hurt. & 2.16 & 1.40 \\
\hline Verbal Bullying & 7.00 & 2.95 \\
\hline - $\quad$ I teased other student(s) and made cruel jokes about him/her. & 2.34 & 1.31 \\
\hline - I told other student(s) that I would hurt him/ her. & 1.97 & 1.26 \\
\hline - $\quad$ I said mean things about other student(s) and called him/her bad names. & 2.69 & 1.41 \\
\hline Relational/Social Bullying & 4.61 & 2.61 \\
\hline - $\quad$ I kept this/those I didn't like from joining in play time or group activities. & 1.63 & 1.06 \\
\hline - $\quad$ I told lies and stories about other student(s) to make him/her look bad. & 1.49 & 0.94 \\
\hline - $\quad$ I kept other student(s) from being friends with people I didn't like. & 1.50 & 0.93 \\
\hline
\end{tabular}

The fifth research question stated "What is the difference in specific forms of bullying scores (physical, verbal, and relational bullying) between school students in Jordan who are males or females?" Regarding physical bullying, independent t-test results revealed that there was a statistically significant difference in scores between males $(M=$ 7.78, $S D=3.25)$, and females $(M=4.09, S D=1.77)$; $[t(399.32)=16.31, p=.00]$. Moreover, there was a statistically significant difference in relational bullying scores for males $(M=4.10, S D=1.88)$, compared to females $(M=5.08, S D=2.13) ;[t(547.02)=-5.65, p=.00]$ (Table 6).

In general, the study results revealed that school students had different levels of perpetrating of physical and relational bullying (males used physical bullying more than females, on the other hand, females used relational bullying more than males), but they had the same level of perpetrating of verbal bullying $(p=0.26$, males and females had equal pattern of using verbal bullying) (Table 6).

Table 6. Comparison between Male and Female students in terms of Physical, Verbal, and Relational (Social) Bullying

\begin{tabular}{llllll}
\hline Variables & M & SD & T & df & P-value \\
\hline Physical Bullying & 5.86 & 3.17 & 16.31 & 399.32 & 0.00 \\
Male & 7.78 & 3.25 & & & \\
Female & 4.09 & 1.77 & & & \\
\hline Verbal Bullying & 7.00 & 2.95 & 1.11 & 541.84 & 0.26 \\
Male & 7.14 & 2.99 & & & \\
Female & 6.86 & 2.91 & & & \\
\hline Relational/Social Bullying & 4.61 & 2.61 & -5.65 & 547.02 & 0.00 \\
Male & 4.10 & 1.88 & & & \\
Female & 5.08 & 2.13 & & & \\
\hline
\end{tabular}

Note. Sig. P-value is less than or equal to.05

\section{Discussion}

The current study found a positive relationship between media violence exposure and school bullying. From the three media forms (TV, movies/ videos/ DVD, and video/ computer games), the highest correlation with school bullying was for videogames violence exposure subscale. This result could be due to the reason that videogames 
have a significant penetration into children's and adolescents' life, with an active role of the child in the development of violent content, or sometimes he/she is the hero of the game; this in turn results in high attractiveness of these media forms to be the main pastime and significant source of learning for children and adolescents (Media Violence Commission, 2012).

Corresponding with the results of the present study, the study that was conducted by Dittrick et al. (2013) to examine the association between bullying in one hand and playing videogames on the other hand. They found that bullying was related to playing violent and mature videogames, based upon both parents' and children's perspective. Moreover, the current study results agree with the results of Lam, Cheng, and Liu (2013) who found that moderate to severe exposure to violent online games was significantly correlated with bullying.

The present study demonstrated that there was a significant relationship between media violence viewing time and school bullying. A reason might be that the media has a vital role in formulating children's behaviors, attitude, and thoughts more than their parents and teachers. The results of the currents study are in the line with a study that found each extra hour of television viewing at the age of 2.4 years led to $10 \%$ unit increase in peer victimization at the age of 10 years (Pagani, Fitzpatrick, Barnett, \& Dubow, 2010).

In the current study, male students viewed violence in the three media forms more than female students. These results might be due to the reason that in eastern culture; boys have more access to watch different forms of media than girls. Boys can watch different media forms in their homes, their friends' homes, internet cafes, and play-station shops, whereas girls can watch media forms only on their homes under the parents' supervision. Regarding media violence exposure subscales; the highest significant difference between males and females was for videogames violence exposure subscale. This result is congruent with the results of Dittrick et al. (2013) which revealed a significant gender difference for children's reports of videogames preference; male children reported preferring games with higher ratings of maturity and violence than girls.

It is worth to mention that the percentage of perpetrating school bullying in the present study was $47 \%$. However, in the current study, male students were more perpetrators of school bullying. This result could be explained by the argument that male students tend to be more active, have a higher preference for violent media, and have a strong need for showing a manhood through behaving aggressively with others, taking risky behaviors, and perseverance. Whereas female students have a higher need for modesty, gentleness, and discipline (Yang, 2012). Results of the present study are consistent with the results of Al-Bitar et al. (2013) which found that the percentage of school bullying was $47 \%$ for being a victim of bullying, and $35 \%$ for bulling someone else. Also, male students were more perpetrators of school bullying than female students.

Overall, the observed pattern of school bullying in the current study reflects that boys reported engaging more in physical bullying, whereas girls reported engaging more in relational/social bullying. The present study revealed also an equal gender use of verbal bullying. The rational of the current results may be due to cultural and social variations between genders, where males use more physical bullying in attempt to display their hegemonic masculinity, popularity, physical strength and independency, while females prefer covert forms of school bullying (relational) rather than the overt one (physical) in attempt to display socially acceptable behaviors in front of their community (Hong \& Espelage, 2012). To some extent, results of the present study are congruent with the results of Dittrick et al. (2013) who found that boys were more perpetrators of general bullying, physical bullying, and verbal bullying than girls.

\section{Study Implications}

Several implications were suggested depending on the results of the current study.

For example, school nurse is responsible for developing and applying bullying prevention programs for children and their parents and teaching them strategies which are suitable for the school climate and cultural norms. Pigozi and Machado (2015) analyzed literature addressing bullying among adolescents in Brazil. They found that many studies emphasized the need for an interdisciplinary approach; between education, health, family, and community. This approach can be directed toward strengthening anti-bullying actions and effectively addressing bullying-related emotional and mental health issues.

Parents can restrict unsupervised media viewing of their children and adolescents through spending more time in shared family-activities, supervising both gaming behaviors and online communications, putting rules over electronic devices being kept in public places in homes, limiting time of using, and installing filtering and protection software. Furthermore, parents should focus on building healthy and friendly relationships with their children, as well as, between children and their peers, to promote the idea of respect and no bullying. It is essential for the parents to discuss with their children what they had seen or heard. This will enable the parents to lessen the 
negative influence of media with violence or other anti-social content on their children's thoughts, cognitive, emotions, and behaviors.

The cross-sectional study in Brazil that measured verbal school bullying indicated that family support is an important factor that can influence adolescents' school bullying. Adolescents who were aggressors and victims demonstrated a low prevalence of family support. The authors recommended demonstration of educational campaigns for schools and families (Serra-Negra et al., 2015). Finally, there is a need to create policies to address bullying and promote training and support educators to deal with bullying in school (Pigozi \& Machado, 2015). Initiatives include construction of policies, legislations, and bullying preventions programs, to prevent further development of this deleterious phenomenon and to ensure that the school environment is healthy, secured, and supportive for learning and education.

\section{Limitations of the Study}

There are some limitations for the current study. First, although the study utilized a random representative sample of Jordanian adolescent students in north of Jordan, no students were sampled form other geographical areas of Jordan (such as middle, and south regions). Second, students may had been reluctant to report their actual aggressive bullying and their true preference for different types of media violence due to social desirability effect. Third, the study was cross-sectional in nature, so causality cannot be assumed. Finally, the students of private schools were excluded due to administrative restrictions which could affect the generalizability study findings.

\section{Recommendations for Future Research}

Despite the previously mentioned limitations, this study was able to contribute to the body of evidence on the link between exposure to media violence and school bullying. Future research is needed to investigate the impact of media violence exposure on other important outcomes which affect adolescents' physical and mental health issues such as: psychopathic traits (e.g., anger, frustration, fear, and depression), aggressive behaviors, academic performance, and sleep disturbance. Moreover, effect of other risk factors such as poor family relationships and contact with delinquent peers, on school bullying could be targeted in future research. This study laid the baseline for future research about the effect of media violence exposure on different aspects of adolescents' health. To enhance generalizability of the findings, future research should include larger sample size from different regions in Jordan, and other educational sectors such as the private schools. To improve validity and rigor of future studies in this topic, it is recommended to use (in addition to self-report) other sources of data such as parents' reports, teachers' reports, and peers' reports.

\section{Conclusion}

The present study results supported the association between media violence exposure and school bullying. Moreover, the current results revealed that the percentage of school bullying is relatively high in Jordan compared to other countries worldwide. This indicates that school bullying represents a serious and growing phenomenon among adolescent students. Intervention programs need to be tailored to be suitable for each school climate and cultural context. Still, the vicious consequences of school bullying coupled with the accumulated body of evidence confirming the relationship between media violence exposure and bullying, demand decisive discussion and further investigations worldwide.

\section{Competing Interests Statement}

The authors declare that there are no competing or potential conflicts of interest regarding the publication of the paper.

\section{References}

Al-Bitar, Z. B., Al-Omari, I. K., Sonbol, H. N., Al-Ahmad, H. T., \& Cunningham, S. J. (2013). Bullying among Jordanian schoolchildren, its effects on school performance, and the contribution of general physical and dentofacial features. American Journal of Orthodontics and Dentofacial Orthopedics, 144(6), 872-878. https://doi.org/10.1016/j.ajodo.2013.08.016

Centers for Disease Control and Prevention. Youth risk behavior surveillance-United States, 2015. Morbidity and Mortality Weekly Report, 65(SS-6), 1-174.

Chan, J. H. F. (2002). The School life survey: a new instrument for assessing school bullying and victimization (Unpublished doctoral dissertation) University of Hull, England.

Den Hamer, A. H., \& Konijn, E. A. (2015). Adolescents' media exposure may increase their cyberbullying behavior: A longitudinal study. Journal of Adolescent Health, 56(2), 203-208. 
https://doi.org/10.1016/j.jadohealth.2014.09.016

Den Hamer, A., Konijn, E. A., \& Keijer, M. G. (2014). Cyberbullying behavior and adolescents' use of media with antisocial content: A cyclic process model. Cyberpsychology, Behavior, and Social Networking, 17(2), 74-81. https://doi.org/10.1089/cyber.2012.0307

Department of statistics in Jordan. Population and housing: demographic statistics-Irbid. Jordan. Retrieved April 23, 2015, from http://www.dos.gov.jo/dos_home_a/main/population/census2015/Persons/Persons_3.1.pdf

Dittrick, C. J., Beran, T. N., Mishna, F., Hetherington, R. \& Shariff, S. (2013). Do children who bully their peers also play violent videogames? A Canadian national study. Journal of School Violence, 12(4), 297-318. https://doi.org/10.1080/15388220.2013.803244

Fanti, K. A., Demetriou, A. G., \& Hawa, V. V. (2012). A longitudinal study of cyberbullying: Examining risk and protective factors. European Journal of Developmental Psychology, 9(2), 168-181. https://doi.org/10.1080/17405629.2011.643169

Fikkers, K. M., Piotrowski, J. T., Weeda, W. D., Vossen, H. G. \& Valkenburg, P. M. (2013). Double dose: High family conflict enhances the effect of media violence exposure on adolescents' aggression. Societies, 3(3), 280-292. https://doi.org/10.3390/soc3030280

Hong, J. S. \& Espelage, D. L. (2012). A review of research on bullying and peer victimization in school: An ecological system analysis. Aggression and Violent Behavior, 17(4), 311-322. https://doi.org/10.1016/j.avb.2012.03.003

Ismail, W. S., Jaafar, N. R., Sidi, H., Midin, M., \& Shah, S. A. (2014). Why do young adolescents bully? Experience in Malaysian schools. Comprehensive Psychiatry, 55, S114-S120. https://doi.org/10.1016/j.comppsych.2013.05.002

Kazarian, S. S. \& Ammar, J. (2013). School bullying in the Arab world: A Review. The Arab Journal of Psychiatry, 24(1), 37-45. https://doi.org/10.12816/0000097

Konijn, E.A., Veldhuis, J., Plaisier, X.S., Spekman, M. \& den Hamer, A. (2015). Adolescent development and psychological mechanisms in interactive media use. The Handbook of the Psychology of Communication Technology. Netherlands: John Wiley \& Sons.

Lam, L. T., Cheng, Z. \& Liu, X. (2013). Violent online games exposure and cyberbullying/ victimization among adolescents. Cyberpsychology, Behavior, and Social Networking, 16(3), 159-165. https://doi.org/10.1089/cyber.2012.0087

Media Violence Commission (2012). Report of media violence commission. Aggressive Behavior, 38(5), 335-41. https://doi.org/10.1002/ab.21443

Orue, I., Bushman, B. J., Calvete, E., Thomaes, S., de Castro, B. O., \& Hutteman, R. (2011). Monkey see, monkey do, monkey hurt: Longitudinal effects of exposure to violence on children's aggressive behavior. Social Psychological and Personality Science, 2(4), 432-437. https://doi.org/10.1177/1948550610396586

Pagani, L.S., Fitzpatrick, C., Barnett, T. A., \& Dubow, E. (2010). Prospective associations between early childhood television exposure and academic, psychological, and physical well-being by middle childhood. Archives of Pediatrics and Adolescent Medicine, 164(5), 425-431. https://doi.org/10.1001/archpediatrics.2010.50

Pigozi, P., \& Machado,A. (2015). Bullying during adolescence in Brazil: an overview. Ciência \& Saúde Coletiva, 20(11), 3509-3522. https://doi.org/10.1590/1413-812320152011.05292014

Serra-Negra, J. M., Paiva, S. M., Bendo, C. B., Fulgêncio, L. B., Lage, C. F., Corrêa-Faria, P., \& Pordeus, I. A. (2015). Verbal school bullying and life satisfaction among Brazilian adolescents: Profiles of the aggressor and the victim. Comprehensive Psychiatry, 57, 132-139. https://doi.org/10.1016/j.comppsych.2014.11.004

Tharp, A.T., Simon, T.R. \& Saul, J. (2012). Preventing violence against children and youth. Journal of Safety Research, 43(4), 291-298. https://doi.org/10.1016/j.jsr.2012.08.014

Ttofi, M. M. \& Farrington, D. P. (2011). Effectiveness of school-based programs to reduce bullying: A systematic and meta-analytic review. Journal of Experimental Criminology, 7(1), 27-56. https://doi.org/10.1007/s11292-010-9109-1

Ukoha, E. K. (2013). Media violence and violent behavior of Nigerian youths: Intervention strategies: Child \& adolescent therapy and e-therapy. IFE PsychologIA: An International Journal, 21(3), 230-237.

Verlinden, M., Tiemeier, H., Veenstra, R., Mieloo, C. L., Jansen, W., Jaddoe, V. W. \& Jansen, P. W. (2014). 
Television viewing through ages 2-5 years and bullying involvement in early elementary school. BMC Public Health, 14(1), 1. https://doi.org/10.1186/1471-2458-14-157

Yang, S. C. (2012). Paths to bullying in online gaming: The effects of gender, preference for playing violent games, hostility, and aggressive behavior on bullying. Journal of Educational Computing Research, 47(3), 235-249. https://doi.org/10.2190/EC.47.3.a

\section{Copyrights}

Copyright for this article is retained by the author(s), with first publication rights granted to the journal.

This is an open-access article distributed under the terms and conditions of the Creative Commons Attribution license (http://creativecommons.org/licenses/by/4.0/). 